\title{
Water vapor isotopes indicating rapid shift among multiple moisture sources for the 2018/2019 winter extreme precipitation events in Southeast China
}

Tao Xu ${ }^{1}$, Hongxi Pang ${ }^{1,2}$, Zhaojun Zhan ${ }^{1}$, Wangbin Zhang ${ }^{1}$, Huiwen Guo ${ }^{1}$, Shuangye $\mathrm{Wu}^{3}$, and Shugui $5 \mathrm{Hou}^{1,4}$

${ }^{1}$ Key Laboratory of Coast and Island Development of Ministry of Education, School of Geography and Ocean Science, Nanjing University, Nanjing, 210023, China

${ }^{2}$ Collaborative Innovation Center of Climate Change, Jiangsu Province, Nanjing, 210023, China

${ }^{3}$ Department of Geology, University of Dayton, Dayton, OH 45469, USA

${ }^{4}$ School of Oceanography, Shanghai Jiao Tong University, Shanghai, 200240, China

Correspondence: H. Pang (hxpang@nju.edu.cn) and S. Hou (shuguihou@sjtu.edu.cn)

\begin{abstract}
In the East Asian monsoon region, winter extreme precipitation events occasionally occur and bring great social and economic losses. From December 2018 to February 2019, Southeast China experienced a record-breaking number of extreme precipitation events. In this study, we analyzed the variation of water vapor isotopes and their controlling factors during the extreme precipitation events in Nanjing, Southeast China. The results show that the variations of water vapor isotopes are closely linked to the change of moisture sources. Using a water vapor d-excess weighted trajectory model, we identified five most important moisture source regions: South China, East China Sea, South China Sea, Bay of Bengal, and Continental regions (Northwest China and Mongolia). Moreover, the variations of water vapor d-excess during a precipitation event reflect rapid shifts of moisture source regions. These results indicate that rapid shifts among multiple moisture sources are important conditions for sustaining wintertime extreme precipitation events over extended periods.
\end{abstract}

\section{Introduction}

South China is under the influenced of the East Asian Winter Monsoon during winter with prevailing northeasterly wind. As a result, winter precipitation is significantly less than summer (Yao et al., 2015), accounting for approximately $10 \%$ of the 
total annual precipitation (Wang and Feng, 2011). However, persistent extreme winter precipitation events still occur

occasionally (Huang et al., 2018a; Li et al., 2020a), such as the disastrous snowstorm in January 2008 (Ding et al., 2008), which caused great losses in agriculture, transportation, and electric power facilities (Zhou et al., 2011). Such extreme events are likely to become more frequent with global warming (Rahmostorf and Coumou, 2011; Qin et al., 2021). Therefore, improving the understanding of the characteristics, controlling factors, and moisture sources of winter extreme precipitation events over South China could have great scientific as well as economic significance.

It is well known that extreme weather events are often caused by a combination of anomalous conditions in multiple atmospheric circulation systems (Li et al., 2019). Previous studies attributed the winter extreme precipitation events over South China to anomalies in the Western Pacific subtropical high, the East Asian major trough, the India-Burma trough, and the formation of the European blocking high (Wang et al., 2000; Zong et al., 2014; Ding and Li, 2017; Huang et al., 2018b). In addition, the variation of winter precipitation was also found to be closely related to sea surface temperature over the Eastern Tropical Indian Ocean and the South China Sea (Zhou et al., 2010; Li et al., 2015a). In addition to dynamic and thermal conditions, abundant moisture supply is also an essential condition for winter extreme precipitation events (Yang et al., 2019; Zhao et al., 2021). Therefore, exploring the moisture sources for the extreme precipitation events is a crucial part of understanding factors controlling these events. Previous climatological studies suggest that the most important moisture source regions for wintertime precipitation in South China were the South China Sea, western North Pacific, and the Bay of

Bengal (Baker et al., 2015; Sun and Wang, 2015). However, detailed information about moisture transport and source regions of individual extreme precipitation events is largely lacking. Moreover, the large-scale atmospheric circulation patterns are not changing significantly at short time scale, so it is difficult for climatological studies to capture the possible rapid switching of moisture sources during an extreme precipitation event.

Stable isotopes in precipitation and water vapor $\left(\delta^{18} \mathrm{O}\right.$ and $\left.\delta^{2} \mathrm{H}\right)$ are useful natural tracers for the hydrological cycle (Araguás-Araguás et al., 2000; Galewsky et al., 2016). They have been used to trace moisture sources (Bonne et al., 2014; He et al., 2016) and identify water vapor transport pathways (Tian et al., 2007; Cai and Tian, 2016). Earlier studies have improved our understanding of the variations of stable isotopic compositions at different time scales, especially at the 
monthly and daily scales. The variability of stable isotopic compositions is not only affected by local meteorological factors, such as temperature and precipitation amount (Dansgaard, 1964; Yu et al., 2015), but also by large-scale atmospheric circulations (Zhou and Li, 2017; Gao et al., 2018), and sources of moisture (Peng et al., 2010; Wang et al., 2017). In addition, deuterium excess (d-excess), defined as $\mathrm{d}=\delta^{2} \mathrm{H}-8 \times \delta^{18} \mathrm{O}$, is influenced by the evaporative and meteorological conditions in the moisture source region (Dansgaard, 1964; Merlivat and Jouzel, 1979), and often used as an indicator for changes in relative humidity at the source region or shifts in the moisture origin (Benetti et al., 2014). Existing studies on precipitation and water vapor isotopes often used monthly and daily data, which do not have the temporal resolution needed to study isotopic changes during individual precipitation events. In addition, continuous collection of precipitation isotope data through precipitation events is often difficult due to adverse weather conditions. Therefore, a continuous monitoring of water vapor isotopes at high temporal resolution (from minutely to hourly timescales) provides a feasible way to identify changes in the moisture sources during precipitation events. Moreover, compared with precipitation, water vapor responds more sensitively to changes in atmospheric circulation (Yao et al., 2018; Li et al., 2020b).

From December 2018 to February 2019, the joint influence of the central Pacific El Niño and East Asian Winter Monsoon quasi-biweekly oscillation led to a long period of persistent rainfall in Southeast China. The 51 accumulated rainy days had the highest regional effective precipitation since 1981 (Guo et al., 2019; Wang et al., 2020). The regional sunshine duration was only half of the normal condition with the lowest number of sunshine hours recorded since 1961 (Li et al., 2020c). This record-breaking event provided an opportunity for using stable isotopes to understand the possible causes and moisture sources of winter extreme precipitation. In this study, we monitored and analyzed the stable isotopic compositions of water vapor (with hourly resolution) and precipitation during this extreme precipitation period in Nanjing, Southeast China. We utilized these high temporal resolution data to investigate the evolution of the stable isotopic compositions in water vapor during this period, and understand how event-scale isotopic variation is affected by climate factors and moisture sources during winter extreme precipitation events. 


\subsection{Study site}

Sampling and measurement of stable isotopes in water vapor and precipitation were carried out at the Station for Observing Regional Processes of the Earth System of Nanjing University (SORPES-NJU, $32.12^{\circ} \mathrm{N}, 118.95^{\circ} \mathrm{E}, 55 \mathrm{~m}$ above sea level) on the Xianlin Campus of the Nanjing University, about 20 km east of downtown Nanjing in Southeast China (Li et al., 2020b).

Nanjing is located in the lower reaches of the Yangtze River in China and has a typical subtropical monsoon climate. Under the influence of the East Asia Monsoon, it has a strongly seasonal climate with hot and rainy summers and cold and dry winters. In the winter (December-February, DJF), Nanjing is under the influence of the East Asian Winter Monsoon. According to the historical meteorological data (1981-2010), the average DJF monthly precipitation is $42 \mathrm{~mm}$. From December 2018 to February 2019, affected by the continuous rainy weather, Nanjing has 46 accumulated rainy days and the total accumulated precipitation is $259 \mathrm{~mm}$, more than double the seasonal average of 1981-2010 (Fig. 1).

\subsection{Sampling and measurement}

Water vapor sampling was carried out on the roof of the SORPES-NJU two-floor building from 1 November 2012 to the present. Data from December 2018 to February 2019 was used for this study. The stable isotopic compositions of water vapor $\left(\delta^{18} \mathrm{O}_{\mathrm{v}}\right.$ and $\left.\delta^{2} \mathrm{H}_{\mathrm{v}}\right)$ were measured by a Picarro Wavelength Scanned Cavity Ring-Down Spectrometer (WS-CRDS, model: Picarro L2120-i). We calibrated the samples against various deviations (such as memory effect, drift effect, and concentration effect), following a set of procedures described in Gu et al., (2019) and Li et al., (2020b). We collected one sample every $2-3$ seconds, and summarized the raw data into hourly averages for this study. The instrumental uncertainties were less than $0.2 \%$ for $\delta^{18} \mathrm{O}_{\mathrm{v}}$ and $1.0 \%$ for $\delta^{2} \mathrm{H}_{\mathrm{v}}$ (Gu et al., 2019).

Along with regular water vapor sampling, precipitation samples were collected on rainy days with an amount $>0.1 \mathrm{~mm}$ from September 2011 to the present. Data from December 2018 to February 2019 was used for this study. All samples were poured into $100-\mathrm{ml}$ polyethylene bottles immediately after collection. In order to avoid evaporation, all samples were refrigerated until being analyzed. The stable isotopic compositions in precipitation $\left(\delta^{18} \mathrm{O}_{\mathrm{p}}\right.$ and $\left.\delta^{2} \mathrm{H}_{\mathrm{p}}\right)$ were measured by a Picarro L2120-i in the Key Laboratory of Coast and Island Development of Ministry of Education. The precision of 
https://doi.org/10.5194/hess-2021-269

Preprint. Discussion started: 12 July 2021

(c) Author(s) 2021. CC BY 4.0 License.

measurements is $0.05 \%$ for $\delta^{18} \mathrm{O}_{\mathrm{p}}$ and $0.5 \%$ for $\delta^{2} \mathrm{H}_{\mathrm{p}}$ (Tang et al., 2015).

\subsection{Trajectory weighted concentration field}

In order to trace moisture source, we used the NOAA Hybrid Single Particle Lagrangian Integrated Trajectory (HYSPLIT) model and calculated backward trajectories of air masses associated with individual extreme precipitation events, using the Global Data Assimilation System (GDAS) with a spatial resolution of $1^{\circ} \times 1^{\circ}$ as the background meteorological data (ftp://ftp.arl.noaa.gov/pub/archives/gdas1). Eight-day backward trajectories were calculated every one hour with the starting height of $1500 \mathrm{~m}$ above ground.

Based on the HYSPLIT results, we calculated the Concentration Weighted Trajectory (CWT) field at $0.5^{\circ} \times 0.5^{\circ}$ resolution to establish potential source regions that influence the isotopic variability of water vapor at the study site (Salamalikis et al., 2015; Bedaso and Wu, 2020; Li et al., 2020b). The CWT $\left(\mathrm{C}_{\mathrm{ij}}\right)$ was calculated with the following equation:

$\mathrm{C}_{\mathrm{ij}}=\frac{\sum_{\mathrm{k}=1}^{\mathrm{K}} \mathrm{C}_{\mathrm{k}} \tau_{\mathrm{ijk}}}{\sum_{\mathrm{k}=1}^{\mathrm{K}} \tau_{\mathrm{jik}}}$,

where $(\mathrm{i}, \mathrm{j})$ are grid indices, $\mathrm{k}$ is the trajectory index, $\mathrm{K}$ is the total number of trajectories that pass each $0.5^{\circ} \times 0.5^{\circ}$ grid, $\mathrm{C}_{\mathrm{k}}$ the concentration (d-excess) measured upon arrival of trajectory $k$, and $\tau_{\mathrm{ijk}}$ the residence time of trajectory $\mathrm{k}$ in grid cell (i,j).

\subsection{Meteorological and reanalysis data}

We obtained long-term monthly mean (1981-2010) and hourly meteorological data (air temperature, precipitation amount, and relative humidity) from December 2018 to February 2019 at Nanjing meteorological station from China Meteorological

Data Service Center. We also used reanalysis data, including $850 \mathrm{hPa}$ zonal and meridional wind components and temperature, from the European Centre for Medium-Range Weather Forecasts (ECMWF) Copernicus Climate Data Store (https://cds.climate.copernicus.eu) and Global Precipitation Climatology Centre (GPCC) precipitation data from the NOAA Physical Sciences Laboratory (https://psl.noaa.gov/data/gridded/).

Unless explicitly noted, the anomalies for climate variables are calculated with respect to the average of 1981-2010. 


\section{Results}

\subsection{Variations of water vapor and precipitation isotopic compositions during precipitation events}

Previous studies typically identified five large-scale precipitation events during the 2018/2019 winter (Li and He, 2019; Xu et al., 2019; Zhao et al., 2019): (a) December 4-11, (b) December 24-30, 2018, (c) January 7-11, (d) February 16-22, and (e) January 27-31, 2019. Figure 2 shows the hourly average $\delta^{18} \mathrm{O}_{v}$ and $d_{v}$, daily average of $\delta^{18} \mathrm{O}_{\mathrm{p}}$ and $\mathrm{d}_{\mathrm{p}}$, and hourly air temperature, relative humidity, and precipitation amount for those five events. $\delta^{18} \mathrm{O}_{v}$ varies from $-23.6 \%$ to $-12.4 \%$ (with an average of $-18.1 \%$ ), and dv ranges from $16.3 \%$ to $35.9 \%$ (with an average of $24.6 \%$ ). $\delta^{18} \mathrm{O}_{\mathrm{p}}$ has an range from $-15.5 \%$ to $-1.3 \%$ and an average of $-7.0 \%$. $d_{p}$ ranges from $13.5 \%$ to $32.5 \%$, with an average of $23.6 \%$. Stable isotopes in precipitation and water vapor have similar variation pattern. Therefore, only high temporal resolution water vapor isotope data are used for further analysis. Based on the large-scale atmospheric circulation patterns (Fig. 3), we group these precipitation events into three classes.

The first class (including event a and b) is defined as cold air mass dominated events. The beginning of the precipitation event was characterized by the southerly wind (Fig. 3a, b) and higher temperature (Fig. 2a, b). With the invasion of the cold air mass through the majority of the event period, the study site experienced northerly wind and temperature decrease. Towards the end of the event, the site returned to southerly wind with temperature increase. Under this circulation background, the $\delta^{18} \mathrm{O}_{\mathrm{v}}$ value was generally high at the beginning, decreased significantly during the events, and gradually increased again toward the end of the events, whereas the $d_{v}$ value showed the opposite trends (Fig. 2a, b). The lowest $\delta^{18} \mathrm{O}_{v}$ and highest $d_{v}$ values were usually observed at the lowest temperature and relative humidity. However, changes in temperature and relative humidity cannot completely explain the variation in the $\delta^{18} \mathrm{O}_{\mathrm{v}}$ and $\mathrm{d}_{\mathrm{v}}$ values. Air temperature and relative humidity data obtained from the meteorological station only reflect the local conditions at the sampling site (He et al., 2018), and the large-scale atmospheric circulation plays a more important role.

The second class (event $\mathrm{c}$ and $\mathrm{d}$ ) is defined as warm air mass dominated events. Northerly wind and low temperature occurred only at the beginning of the precipitation event, whereas the majority of the even period was characterized by southerly wind and warm temperature (Fig. 3 c, d). Similar to the first class, the $\delta^{18} \mathrm{O}_{v}$ value was generally high at the 
beginning, decreased significantly during the events, and gradually increased again toward the end of the events (Fig. 2c).

However, different from the first class, both $\delta^{18} \mathrm{O}_{\mathrm{v}}$ and $\mathrm{dv}$ values in this class showed many more fluctuations throughout the event (Fig. 2c, d). The lowest $\delta^{18} \mathrm{O}_{\mathrm{v}}$ and $\mathrm{d}_{\mathrm{v}}$ values occurred at the lowest temperature and highest relative humidity, it is significantly different from the first class.

In addition to the above two classes, the third class (event e) is characterized by alternating cold and warm air masses. The event started with northerly wind and low temperature, followed by southerly wind and temperature increase, and ended with northerly wind and temperature decrease (Fig. 3e). The $\delta^{18} \mathrm{O}_{\mathrm{v}}$ value remained constant in the early stage until it decreased suddenly at the end, whereas the $d_{v}$ value showed great fluctuations (Fig. 2e).

\subsection{Intra-event variation of water vapor isotopic compositions}

Significant variations in $\delta^{18} \mathrm{O}_{\mathrm{v}}$ and $\mathrm{d}_{\mathrm{v}}$ values of water vapor are observed within each event. We used the concentrated rainfall period of each event and divided it into different stages (Fig. 2), based on the above three classifications and the temporal patterns of variation in water vapor $\delta^{18} \mathrm{O}_{\mathrm{v}}$ and $\mathrm{d}_{\mathrm{v}}$.

The first class (Fig. 2a, b) of the precipitation events can be divided into four stages. (In the last stage of event $b$ was not delineated because of missing data.) In stages 1 and 2, the $\delta^{18} \mathrm{O}_{\mathrm{v}}$ values continued to decrease, which was consistent with the temperature effect (i.e. stable isotopes had a significant positive correlation with air temperature). The $d_{v}$ value first decreased (or remained stable), then increased, suggesting a gradual shift of water vapor source from ocean to land (Fig. 2a, b). Generally, atmospheric water vapor from the dry and cold regions shows a more negative $\delta^{18} \mathrm{O}$ value and relatively high d-excess value (Uemura et al., 2008; Kostrova et al., 2020). In stage 3, the $\delta^{18} \mathrm{O}_{\mathrm{v}}$ and $\mathrm{d}_{\mathrm{v}}$ value fluctuated without any obvious trends as a whole, mainly due to the mixing of oceanic and inland water vapor. In stage 4 , the $\delta^{18} \mathrm{O}_{\mathrm{v}}$ value continued to decline, consistent with the rainout effect (i.e. stable isotopes continued to decrease with the increase of precipitation amount); the $d_{v}$ value was significantly lower than the stage 3 with no obvious trend, reflecting the stable influence of oceanic water vapor (Fig. 2a).

The second class (Fig. 2c, d) of the precipitation events can be divided into three stages. In stage 1 , the $\delta^{18} \mathrm{O}_{\mathrm{v}}$ value continued to decrease, consistent with the rainout effect; the $d_{v}$ value continued to decrease, suggesting a shift of water vapor 
source from land to ocean. In stage 2 , both the $\delta^{18} \mathrm{O}_{\mathrm{v}}$ value and $\mathrm{d}_{\mathrm{v}}$ values increased, but still lower than the initial value in stage 1, suggesting increasing contribution of local inland water vapor in the mixture of oceanic and inland water vapor. In

stage 3 , the $\delta^{18} \mathrm{O}_{\mathrm{v}}$ value and $\mathrm{d}_{\mathrm{v}}$ values showed a downward trend, reflecting the continuous influence of oceanic water vapor.

The third class (Fig. 2e) of the precipitation event can be divided into two stages. The $\delta^{18} \mathrm{O}_{\mathrm{v}}$ value was stable and relatively high in stage 1, possibly due to the influence of local inland water vapor in South China, where the air temperature remained high, leading to enriched isotopic values. The $\delta^{18} \mathrm{O}_{\mathrm{v}}$ value started to decline in stage 2, likely caused by the rainout effect. The $d_{v}$ value is relatively high in stage 1 , likely due the contribution of local inland water vapor. The rapid decrease of $d v$ in the middle may indicate the influence of oceanic water vapor. In stage 2 , the $d_{v}$ value decreases rapidly, reflecting the rapid change of moisture sources, and a shift from mixed water vapor to oceanic water vapor.

\section{Discussion}

\subsection{Moisture sources for five precipitation events}

Previous studies demonstrated that seasonal variations in the stable isotopic compositions of precipitation are caused not only by local meteorological conditions (Dansgaard, 1964), but also by the different moisture sources (Bonne et al., 2020). The above analysis results show that the large-scale circulation patterns ( $850 \mathrm{hPa}$ meridional wind and temperature) have an important influence on the event-scale stable isotopes in water vapor, and the variation of meridional wind often corresponds to the change of moisture source regions. Some studies indicated that the air masses could obtain specific isotopic signatures based on the meteorological conditions in the moisture source region before reaching a given sampling site (Salamalikis et al., 2015; Kostrova et al., 2020). Therefore, based on the CWT model, we calculated the $\mathrm{d}_{\mathrm{v}}$ value concentration fields to investigate differences among moisture source regions and water vapor transport pathways.

As seen in Fig. 4, we identified five major moisture source regions that affect the sampling site base on cluster analysis of backward trajectories during these precipitation events: South China, East China Sea, South China Sea, Bay of Bengal, and Continental regions (Northwest China and Mongolia). The air parcels passing areas indicated with warm colors exhibit high d-excess values in the sampling site (Salamalikis et al., 2015). Trajectories passing North China, Northwest China, and 
Mongolia correspond to higher $d_{v}$ values in the sampling site (Fig. 4), as they are associated with relatively dry air masses from the inland region. Moisture from other sources show lower $d_{v}$ values, due to higher relative humidity at the oceanic source regions (Fig. 4). These results clearly indicate that the changes of moisture source regions could play an important role in the variation of water vapor isotopic compositions in winter extreme precipitation events. Our observations are in good agreement with the observation of summer extreme precipitation event by Li et al., (2015b). We believe that abundant moisture supply through multiple moisture sources is one of the necessary conditions for the 2018/2019 winter extreme precipitation events to last for a long time.

\subsection{Rapid shift of moisture sources during a precipitation event}

Fig. 2 shows the variation of stable isotopic values in different stages of the precipitation events divided by vertical blue dashed lines. From the above analysis, it can be seen that the intra-event variation of stable isotopic values in water vapor was mainly controlled by the change of moisture sources. Therefore, we believe that the turning points at the blue dashed lines reflected rapid shifts of moisture source regions. In order to verify this hypothesis, we plotted the relationship between the $\mathrm{d}_{\mathrm{v}}$ value and $850 \mathrm{hPa}$ wind direction in the study region. Figure 5 shows that variation of the $\mathrm{d}_{\mathrm{v}}$ value is closely related to rapid change in the wind direction, especially near the turning point. For example, during event a (Fig. 5a), the $d_{v}$ value was relatively low in the early stage, and the main wind directions are easterly and southeasterly, reflecting the influence of water vapor from the East China Sea. From the first vertical blue dashed line, the wind direction turned northerly. As a result, the $d_{v}$ value gradually increased and remained high, mainly due to the influence of water vapor transported by cold air mass from Northwest China and Mongolia. In the later stage, the wind direction near the second vertical blue dashed line turned to southerly and southeasterly, and the $d_{v}$ value decreased due to the water vapor from the East China Sea. Therefore, the high temporal resolution $d_{v}$ value in water vapor can be used to identify the rapid shift of moisture source regions during the continuous extreme precipitation process.

\section{Conclusions}

In this study, we presented stable isotopes in atmospheric water vapor and precipitation for five extreme winter precipitation 
events in Nanjing, from December 2018 to February 2019. Our analyses suggest that the variations of water vapor isotope are largely influenced by the change of moisture sources. Based on the results of the CWT model, the sampling site received different proportions of water vapor from multiple sources throughout the study period, including South China, East China Sea, South China Sea, Bay of Bengal, and Continental regions (Northwest China and Mongolia). In particular, the turning points of the water vapor d-excess during a precipitation event reflected the rapid shift of moisture source regions. Our results imply that multiple moisture sources and the rapid shift among them are important conditions for sustaining extreme precipitation events, especially in the relatively cold and dry winter.

Data availability. The dataset of daily water vapor $\delta^{18} \mathrm{O}_{\mathrm{v}}$ and $\delta^{2} \mathrm{H}_{\mathrm{v}}$, air temperature, water vapor concentration, relative humidity, precipitation amount, and precipitation $\delta^{18} \mathrm{O}_{\mathrm{p}}$ and $\delta^{2} \mathrm{H}_{\mathrm{p}}$ at Nanjing are available at https://data.tpdc.ac.cn/en/data/d117f51c-b47f-4bfd-9030-0c54f15067cf/.

Author contribution. Hongxi Pang and Shugui Hou conceived this study. Material preparation, data collection, and analysis were performed by Tao Xu, Zhaojun Zhan, and Wangbin Zhang. The first draft of the manuscript was written by Tao Xu. All authors contributed to a discussion of the results.

Competing interests. The authors declare that they have no conflicts of interest.

Acknowledgements. This work was supported by the Natural Science Foundation of China (41771031, 91837102, 41830644) and the Priority Academic Program Development of Jiangsu Higher Education Institutions (PAPD). We would also like to thank the NOAA Air Resource Laboratory (ARL) for providing the HYSPLIT model used in this paper.

\section{References}

Araguás-Araguás, L., Froehlich, K., and Rozanski, K.: Deuterium and oxygen-18 isotope composition of precipitation and 
atmospheric moisture, Hydrol. Process., 14, 1341-1355, https://doi.org/10.1002/1099-1085(20000615)14:8<1341::AID-HYP983>3.0.CO;2-Z, 2000.

Baker, A., Sodemann, H., Baldini, J., Breitenbach, S., Johnson, K., Hunen, J. V., and Zhang, P. Z.: Seasonality of westerly moisture transport in the East Asian summer monsoon and its implications for interpreting precipitation $\delta^{18} \mathrm{O}, \mathrm{J}$. Geophys. Res.-Atmos., 120, 5850-5862, https://doi.org/10.1002/2014JD022919, 2015.

Bedaso, Z. and Wu, S. Y.: Daily precipitation isotope variation in Midwestern United States: Implication for hydroclimate and moisture source, Sci. Total. Environ., 713, 136631, https://doi.org/10.1016/j.scitotenv.2020.136631, 2020.

Benetti, M., Reverdin, G., Pierre, C., Merlivat, L., Risi, C., Steen-Larsen, H. C., and Vimeux, F.: Deuterium excess in marine water vapor: Dependency on relative humidity and surface wind speed during evaporation, J. Geophys. Res.-Atmos., 119, 584-593, https://doi.org/10.1002/2013JD020535, 2014.

Bonne, J. L., Masson-Delmotte, V., Cattani, O., Delmotte, M., and Steen-Larsen, H. C.: The isotopic composition of water vapour and precipitation in Ivittuut, southern Greenland, Atmos. Chem. Phys., 14, 4419-4439, https://doi.org/10.5194/acp-14-4419-2014, 2014.

Bonne, J. L., Meyer, H., Behrens, M., Boike, J., Kipfstuhl, S., Rabe, B., Schmidt, T., Schönicke, L., Steen-Larsen, H. C., and Werner, M.: Moisture origin as a driver of temporal variabilities of the water vapour isotopic composition in the Lena River Delta, Siberia, Atmos. Chem. Phys., 20, 10493-10511, https://doi.org/10.5194/acp-20-10493-2020, 2020.

Cai, Z. and Tian, L.: Processes governing water vapor isotope composition in the Indo-Pacific region: Convection and water vapor transport, J. Climate., 29, 8535-8546, https://doi.org/10.1175/JCLI-D-16-0297.1, 2016.

Dansgaard, W.: Stable isotopes in precipitation, Tellus., 16, 436-468, https://doi.org/10.3402/tellusa.v16i4.8993, 1964.

Ding, F. and Li, C.: Subtropical westerly jet waveguide and winter persistent heavy rainfall in south China, J. Geophys. Res.-Atmos., 122, 7385-7400, https://doi.org/10.1002/2017JD026530, 2017.

Ding, Y., Wang, Z., Song, Y., and Zhang, J.: Causes of the unprecedented freezing disaster in January 2008 and its possible association with the global warming, Acta. Meteorol. Sin., 66, 808-825, 2008 (in Chinese with English abstract).

Gao, J., He, Y., Masson-Delmotte, V., and Yao, T.: ENSO effects on annual variations of summer precipitation stable isotopes 
https://doi.org/10.5194/hess-2021-269

in Lhasa, southern Tibetan Plateau, J. Climate., 31, 1173-1182, https://doi.org/10.1175/JCLI-D-16-0868.1, 2018.

Galewsky, J., Steen-Larsen, H. C., Field, R. D., Worden, J., Risi, C., and Schneider, M.: Stable isotopes in atmospheric water vapor and applications to the hydrologic cycle, Rev. Geophys., 54, 809-865, https://doi.org/10.1002/2015RG000512, 2016.

Gu, X., Pang, H., Li, Y., Zhang, W., and Wang, J.: Study on calibration method for atmospheric water vapor stable isotopes observed by cavity ring-down spectroscopy, Spectrosc. Spect. Anal., 39, 1700-1705, 2019.

Guo, L., Liu, B., and Zhu, C.: Extraordinary long wet spell in south of Yangtze River during 2018/2019 winter and its possible causes, Chinese. Sci. Bull., 64, 3498-3509, https://doi.org/10.1360/N972019-00357, 2019 (in Chinese with English abstract).

He, S. and Richards, K.: Stable isotopes in monsoon precipitation and water vapour in Nagqu, Tibet, and their implications for monsoon moisture, J Hydrol., 540, 615-622, https://doi.org/10.1016/j.jhydrol.2016.06.046, 2016.

He, S., Goodkin, N. F., Kurita, N., Wang, X., and Rubin, C. M.: Stable isotopes of precipitation during tropical Sumatra squalls in Singapore, J. Geophys. Res.-Atmos., 123, 3812-3829, https://doi.org/10.1002/2017JD027829, 2018.

Huang, W., He, X., Yang, Z., Qiu, T., Wright, J. S., Wang, B., and Lin, D.: Moisture sources for wintertime extreme precipitation events over South China during 1979-2013, J. Geophys. Res.-Atmos., 123, 6690-6712, https://doi.org/10.1029/2018JD028485, 2018a.

Huang, W., Yang, Z., He, X., Lin, D., Wang, B., Wright, J. S., Chen, R., Ma, W., and Li, F.: A possible mechanism for the occurrence of wintertime extreme precipitation events over South China, Clim. Dynam., 52, 2367-2384, https://doi.org/10.1007/s00382-018-4262-8, 2018b.

Kostrova, S. S., Meyer, H., Fernandoy, F., Werner, M., and Tarasov, P. E.: Moisture origin and stable isotope characteristics of precipitation in southeast Siberia, Hydrol. Process., 34, 51-67, https://doi.org/10.1002/hyp.13571, 2020.

Li, X., Li, J., and Li, Y.: Recent winter precipitation increase in the Middle-Lower Yangtze River Valley since the Late 1970s: A response to warming in the Tropical Indian Ocean, J. Climate., 28, 3857-3879, https://doi.org/10.1175/JCLI-D-14-00701.1, 2015a. 
Li, J., Tao, T., Pang, Z., Tan, M., Kong, Y., Duan, W., and Zhang, Y.: Identification of different moisture sources through isotopic monitoring during a storm event, J. Hydrometeorl., 16, 1918-1927, https://doi.org/10.1175/JHM-D-15-0005.1, $2015 b$

Li, C., Yang, H., and Zhao, J.: Combinational anomalies of atmospheric circulation system and occurrences of extreme weather/climate events, Trans. Atmos. Sci., 42, 321-333, https://doi.org/10.13878/j.cnki.dqkxxb.20190302001, 2019 (in Chinese with English abstract).

Li, X. and He, L.: Analysis of the February 2019 Atmospheric Circulation and Weather, Meteor. Mon., 45, 738-744, 2019 (in Chinese with English abstract).

Li, X., Wang, C., Ling, T., Sun, C., Zhang, Y., and Wang, J.: Features and possible causes of the extreme precipitation anomaly in China during winter 2019/2020, Front. Earth. Sci., 8, 596753, https://doi.org/10.3389/feart.2020.596753, 2020a.

Li, Y., An, W., Pang, H., Wu, S. Y., Tang, Y., Zhang, W., and Hou, S.: Variations of stable isotopic composition in atmospheric water vapor and their controlling factors-A 6-Year continuous sampling study in Nanjing, Eastern China, J. Geophys. Res.-Atmos., 125, e2019JD031697, https://doi.org/10.1029/2019JD031697, 2020 b.

Li, X., Wen, Z., and Huang, W.: Modulation of South Asian Jet wave train on the extreme winter precipitation over Southeast China: Comparison between 2015/16 and 2018/19, J. Climate., 33, 4065-4081, https://doi.org/10.1175/JCLI-D-19-0678.1, 2020c.

Merlivat. L. and Jouzel. J.: Global climatic interpretation of the deuterium-oxygen 18 relationship for precipitation, J. Geophys. Res., 84, 5029-5033, https://doi.org/10.1029/JC084iC08p05029, 1979.

Peng, T. R., Wang, C. H., Huang, C. C., Fei, L. Y., Chen, C. T. A., and Hwong, J. L.: Stable isotopic characteristic of Taiwan's precipitation: A case study of western pacific monsoon region, Earth. Planet. Sc. Lett., 289, 357-366, https://doi.org/10.1016/j.epsl.2009.11.024, 2010.

Qin, P., Xie, Z., Zou, J., Liu, S., and Chen, S.: Future precipitation extremes in China under climate change and their physical quantification based on a regional climate model and CMIP5 model simulations, Adv. Atmos. Sci., 38, 
https://doi.org/10.5194/hess-2021-269

Preprint. Discussion started: 12 July 2021

(c) Author(s) 2021. CC BY 4.0 License.

460-479, https://doi.org/10.1007/s00376-020-0141-4, 2021.

Rahmstorf, S. and Coumou, D.: Increase of extreme events in a warming world, P. Natl. Acad. Sci. USA., 108, 17905-17909, https://doi.org/10.1073/pnas.1101766108, 2011.

Salamalikis, V., Argiriou, A. A., and Dotsika, E.: Stable isotopic composition of atmospheric water vapor in Patras, Greece: A concentration weighted trajectory approach, Atmos. Res., 152, 93-104, https://doi.org/10.1016/j.atmosres.2014.02.021, 2015.

Sun, B. and Wang, H.: Analysis of the major atmospheric moisture sources affecting three sub-regions of East China, Int. J. Climatol., 35, 2243-2257, https://doi.org/10.1002/joc.4145, 2015.

Tang, Y., Pang, H., Zhang, W., Li, Y., Wu, S., and Hou, S.: Effects of changes in moisture source and the upstream rainout on stable isotopes in precipitation—A case study in Nanjing, eastern China, Hydrol. Earth. Syst. Sci., 19, 4293-4306, https://doi.org/10.5194/hess-19-4293-2015, 2015.

Tian, L., Yao, T., Macclune, K., White, J., Schilla, A., Vaughn, B., Vachon, R., and Ichiyanagi, K.: Stable isotopic variations in west China: A consideration of moisture sources, J. Geophys. Res.-Atmos., 112, D10112, https://doi.org/10.1029/2006JD007718, 2007.

Uemura, R., Matsui, Y., Yoshimura, K., Motoyama, H., and Yoshida, N.: Evidence of deuterium excess in water vapor as an indicator of ocean surface conditions, J. Geophys. Res.-Atmos., 113, D19114, https://doi.org/10.1029/2008JD010209, 2008.

Wang, B., Wu, R. G., and Fu, X. H.: Pacific-East Asian teleconnection: How does ENSO affect East Asian climate? J. Climate., 13, 1517-1536, https://doi.org/10.1175/1520-0442(2000)013<1517:PEATHD>2.0.CO;2, 2000.

Wang, L. and Feng, J.: Two major modes of the wintertime precipitation over China, Chin. J. Atmos. Sci., 35, 1105-1116, https://doi.org/10.3878/j.issn.1006-9895.2011.06.10, 2011 (in Chinese with English abstract).

Wang, S., Zhang, M., Crawford, J., Hughes, C. E., Du, M., and Liu, X.: The effect of moisture source and synoptic conditions on precipitation isotopes in arid central Asia, J. Geophys. Res.-Atmos., 122, 2667-2682, https://doi.org/10.1002/2015JD024626, 2017. 
https://doi.org/10.5194/hess-2021-269

Preprint. Discussion started: 12 July 2021

(c) Author(s) 2021. CC BY 4.0 License.

Wang, Z., Sun, J., Wu, J., Ning, F., and Chen, W.: Attribution of persistent precipitation in the Yangtze-Huaihe river basin during February 2019, Adv. Atmos. Sci., 37, 1389-1404, https://doi.org/10.1007/s00376-020-0107-6, 2020.

Xu, R., Zhang, T., Rao, X., and You, Y.: Analysis of the December 2018 Atmospheric Circulation and Weather, Meteor. Mon., 45, 437-444, 2019 (in Chinese with English abstract).

Yang, Z., Huang, W., He, X., Wang, Y., Qiu, T., Wright, J. S., and Wang, B.: Synoptic conditions and moisture sources for extreme snowfall events over East China, J. Geophys. Res.-Atmos., 124, 601-623, https://doi.org/10.1029/2018JD029280, 2019.

Yao, T., Zhang, X., Guan, H., Zhou, H., Hua, M., and Wang, X.: Climatic and environmental controls on stable isotopes in atmospheric water vapor near the surface observed in Changsha, China, Atmos. Environ., 189, 252-263, https://doi.org/10.1016/j.atmosenv.2018.07.008, 2018.

Yao, Y., Lin, H., and Wu, Q.: Subseasonal variability of precipitation in China during boreal winter, J. Climate., 28, 65486559, https://doi.org/10.1175/JCLI-D-15-0033.1, 2015.

Yu, W., Tian, L., Ma, Y., Xu, B., and Qu, D.: Simultaneous monitoring of stable oxygen isotope composition in water vapour and precipitation over the central Tibetan Plateau, Atmos. Chem. Phys., 15, 10251-10262, https://doi.org/10.5194/acp-15-10251-2015, 2015.

Zhao, Y., Gui, H., Li, S., and You, Y.: Analysis of the January 2019 Atmospheric Circulation and Weather, Meteor. Mon., 45, 587-592, 2019 (in Chinese with English abstract).

Zhao, N., Manda, A., Guo, X., Kikuchi, K., Nasuno, T., Nakano, M., Zhang, Y., and Wang, B.: A Lagrangian view of moisture transport related to the heavy rainfall of July 2020 in Japan: Importance of the moistening over the subtropical regions, Geophys. Res. Lett., 48, e2020GL091441, https://doi.org/10.1029/2020GL091441, 2021.

Zhou, B., Gu, L., Ding, Y., Shao, L., Wu, Z., Yang, X., Li, C., Li, Z., Wang, X., Cao, Y., Zeng, B., Yu, M., Wang, M., Wang, S., Sun, H., Duan, A., An, Y., Wang, X., and Kong, W.: The great 2008 Chinese ice storm: Its socioeconomic-ecological impact and sustainability lessons learned, B. Am. Meteorol. Soc., 92, 47-60, https://doi.org/10.1175/2010BAMS2857.1, 2011. 
https://doi.org/10.5194/hess-2021-269

Preprint. Discussion started: 12 July 2021

(c) Author(s) 2021. CC BY 4.0 License.

Zhou, J. and Li, T.: A tentative study of the relationship between annual $\delta^{18} \mathrm{O} \& \delta \mathrm{D}$ variations of precipitation and atmospheric circulations-A case from Southwest China, Quatern. Int., 479, 117-127, https://doi.org/10.1016/j.quaint.2017.05.038, 2017.

Zhou, L., Tam, C. Y., Zhou, W., and Chan, J. C. L.: Influence of South China Sea SST and the ENSO on winter rainfall over South China, Adv. Atmos. Sci., 27, 832-844, https://doi.org/10.1007/s00376-009-9102-7, 2010.

Zong, H., Bueh, C., Ji, L.: Wintertime extreme precipitation event over southern China and its typical circulation features. Chinese. Sci. Bull., 59, 1036-1044, https://doi.org/10.1007/s11434-014-0124-x, 2014. 


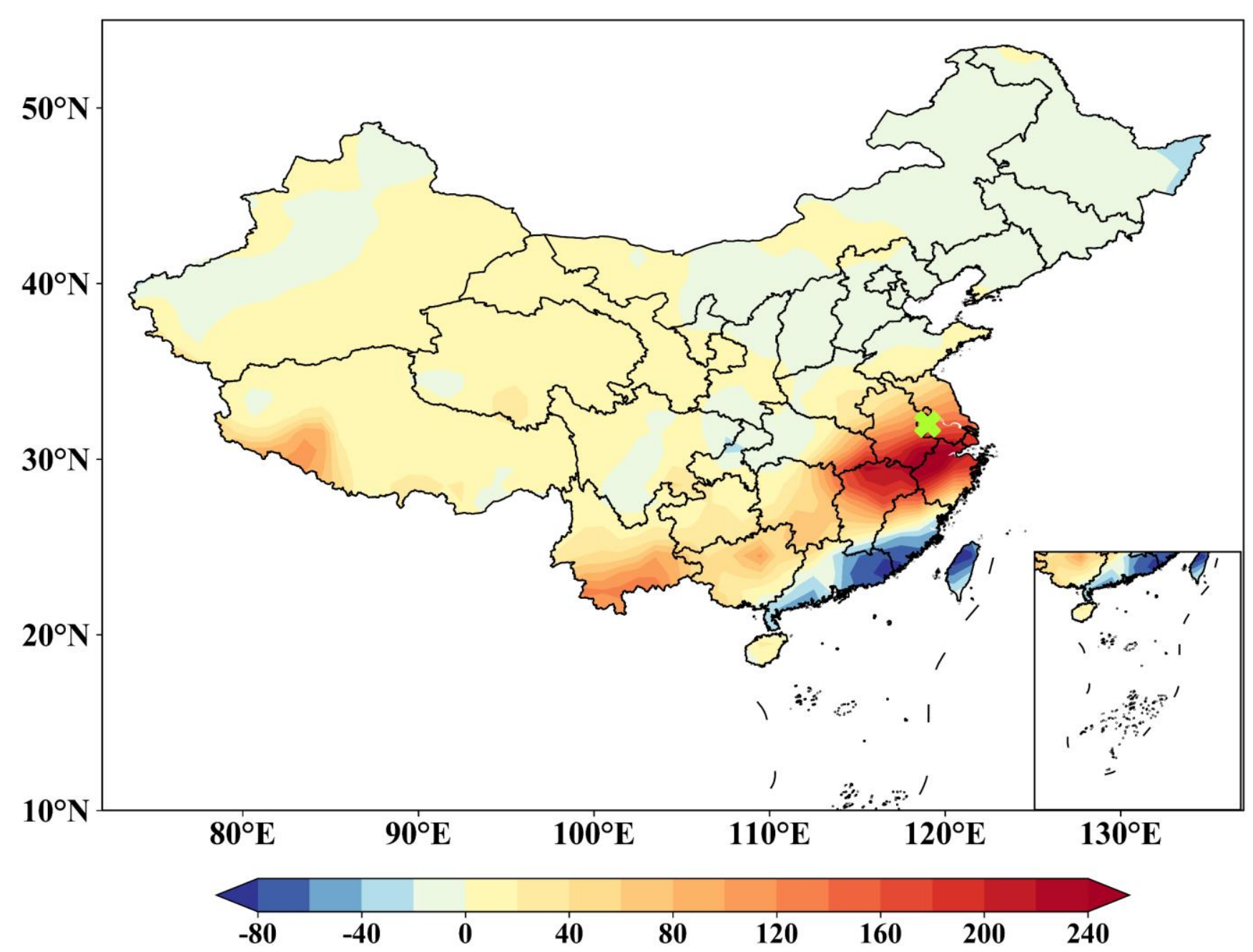

Fig 1. Winter (December-February) precipitation anomalies (shading; units: $\mathrm{mm}$ ) over China in the winter of 2018/2019. " $\mathrm{X}$ " represents the sampling site at Nanjing. The anomalies were calculated with respect to the 1981-2010 climatology. 

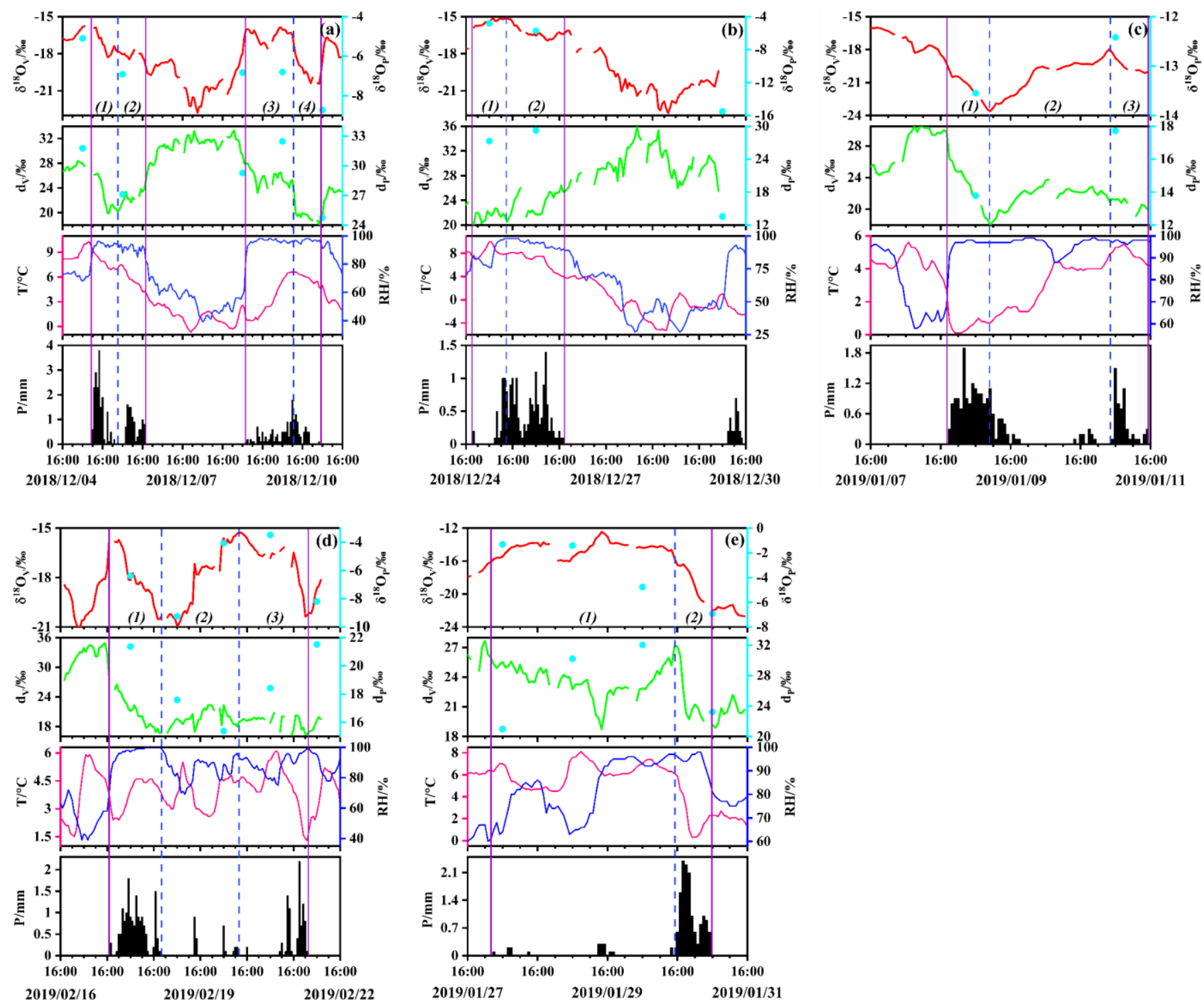

Fig 2. Time series of hourly water vapor $\delta^{18} \mathrm{O}_{v}$ and $d_{v}$, daily precipitation $\delta^{18} \mathrm{O}_{\mathrm{p}}$ and d $d_{\mathrm{p}}$ (cyan dots), air temperature (T), relative humidity (RH), and precipitation amount (P) at Nanjing. (a) Event December 4-11, 2018; (b) Event December 24-30, 2018; (c) Event January 7-11, 2019; (d) Event February 16-22, 2019; (e) Event January 27-31, 2019. The vertical purple lines and blue dashed lines indicate the concentrated rainfall period and different stages of each precipitation event, respectively. 

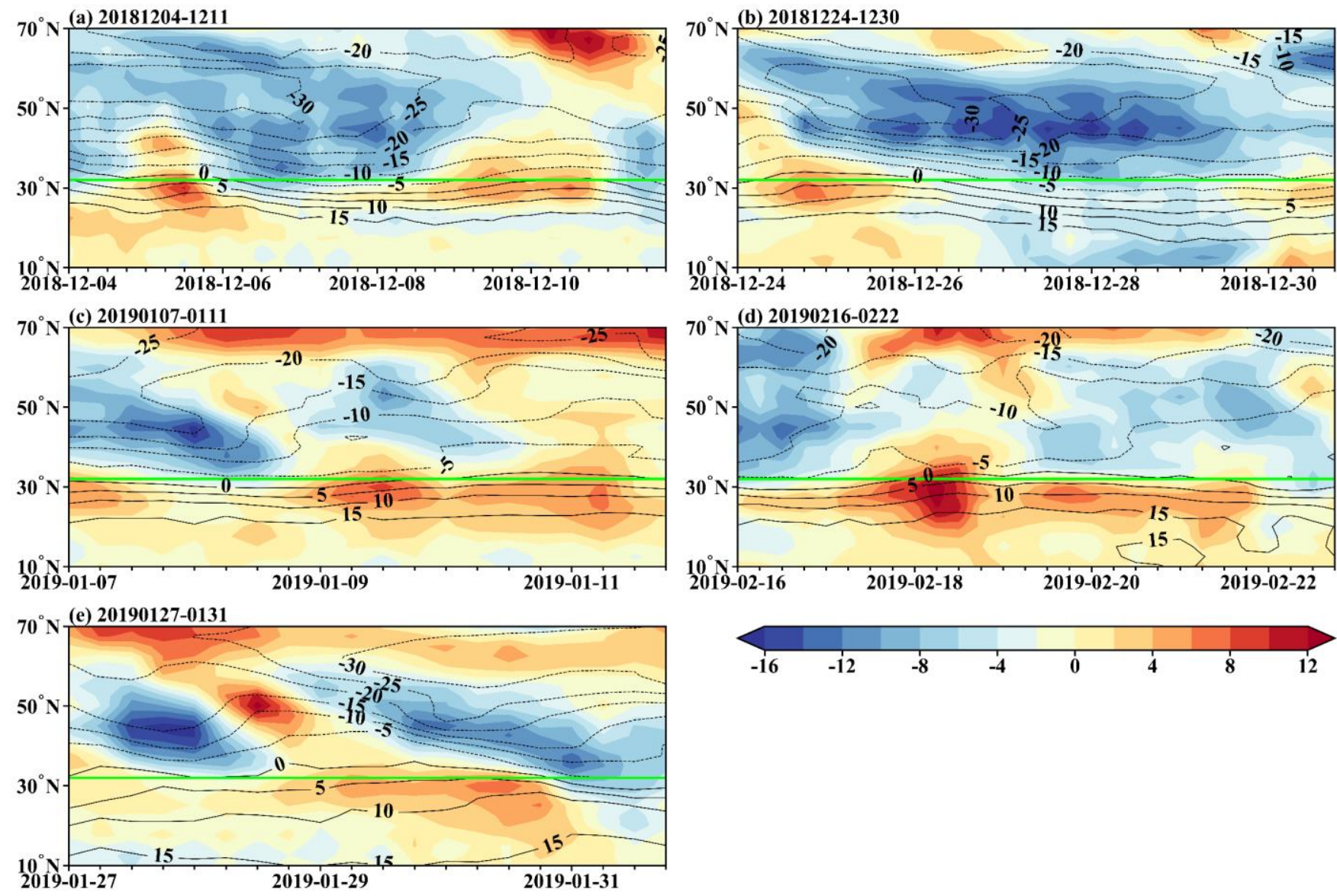

Fig 3. Latitude-time cross section of the meridional wind component (shading; units: $\mathrm{m} / \mathrm{s}$ ) and temperature (contour; units: ${ }^{\circ} \mathrm{C}$ ) at $850 \mathrm{hPa}$ along the $120^{\circ} \mathrm{E}$. The horizontal green lines indicate the latitude of the sampling site at $\mathrm{Nanjing}\left(32.12^{\circ} \mathrm{N}\right)$. 
https://doi.org/10.5194/hess-2021-269

Preprint. Discussion started: 12 July 2021

(c) Author(s) 2021. CC BY 4.0 License.

(c) (i)
Hydrology and

Earth System

Sciences

Discussions (a) 20181204-1211

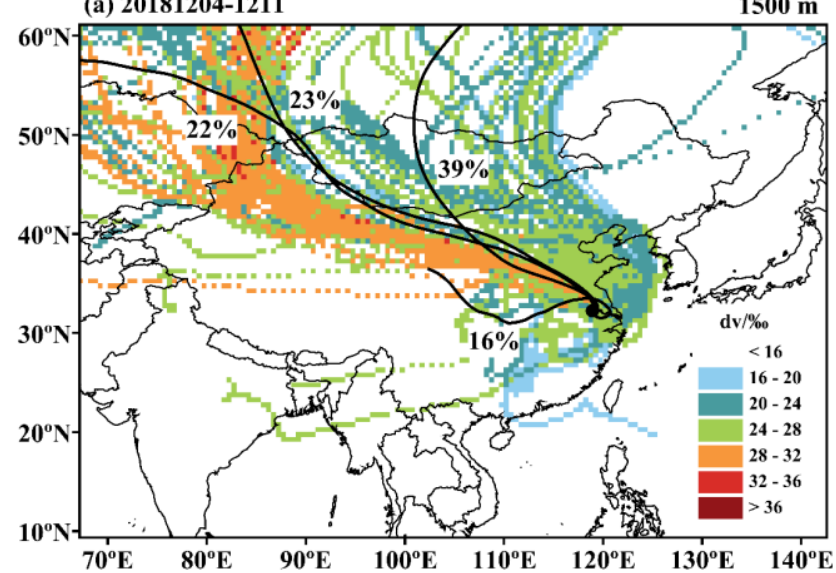

(c) 20190107-0111

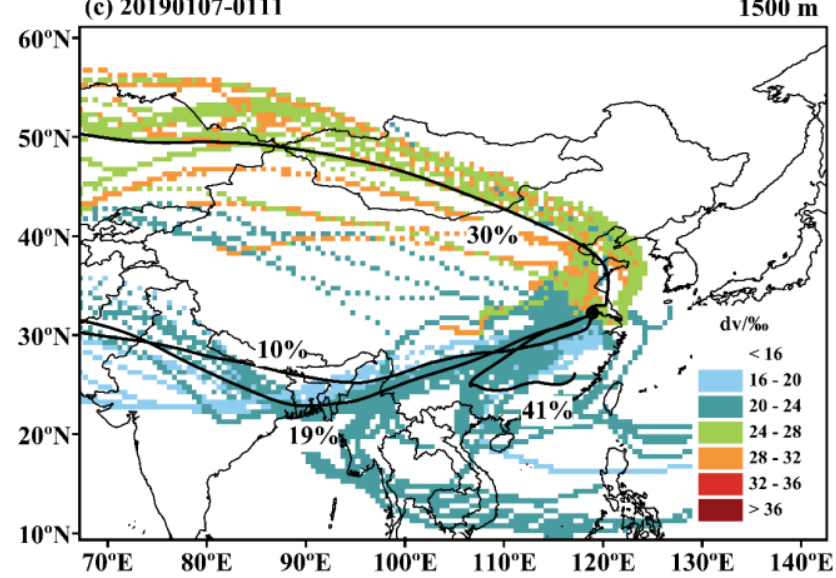

(e) 20190127-0131

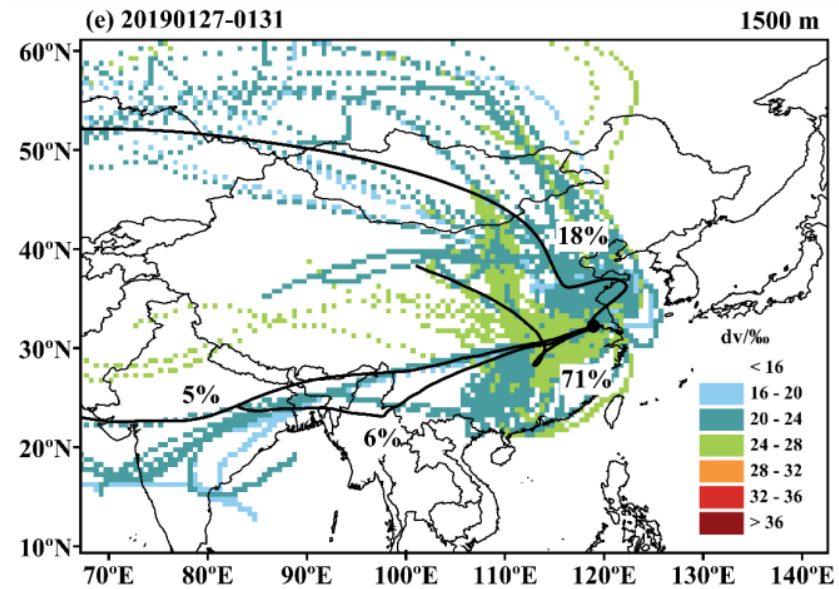

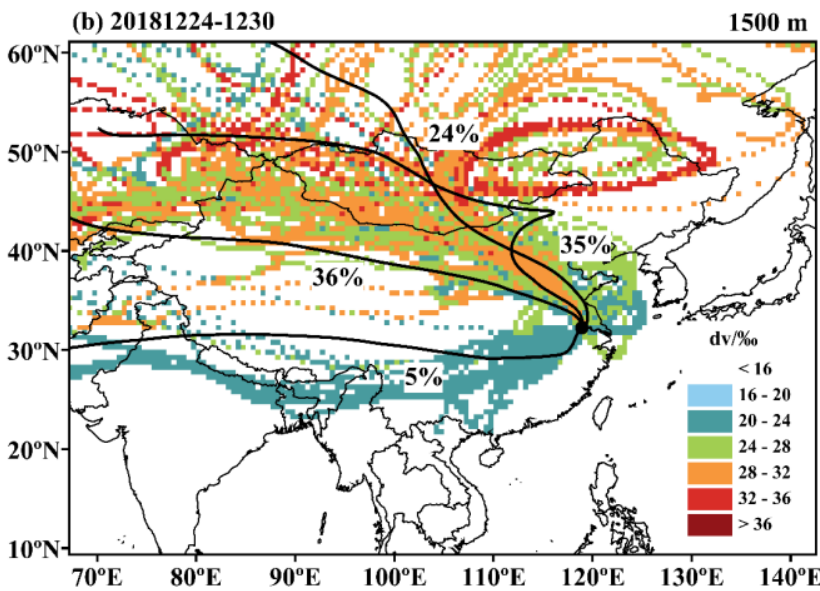

(d) 20190216-0222

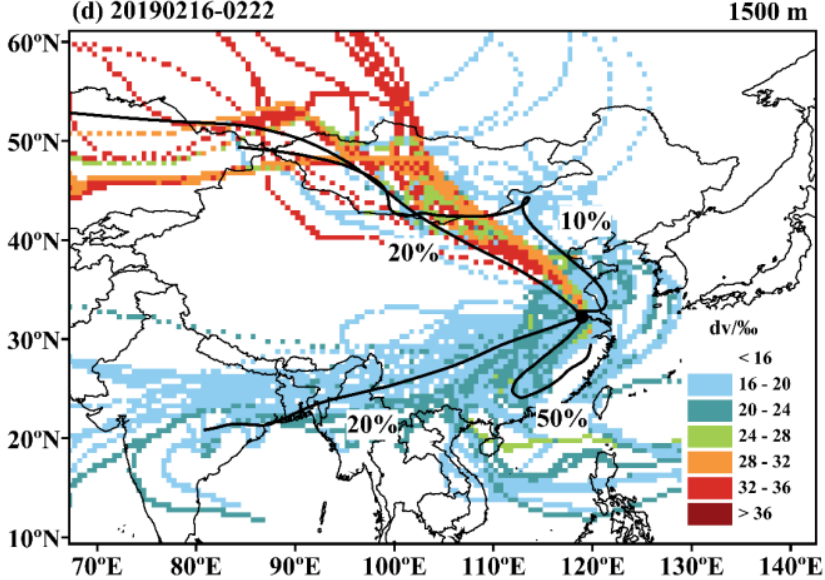

Fig 4. Concentration field of water vapor $d_{v}$ for $192 \mathrm{~h}$ HYSPLIT back trajectories and clusters for the five typical precipitation events. The black circle indicates the location of Nanjing. 

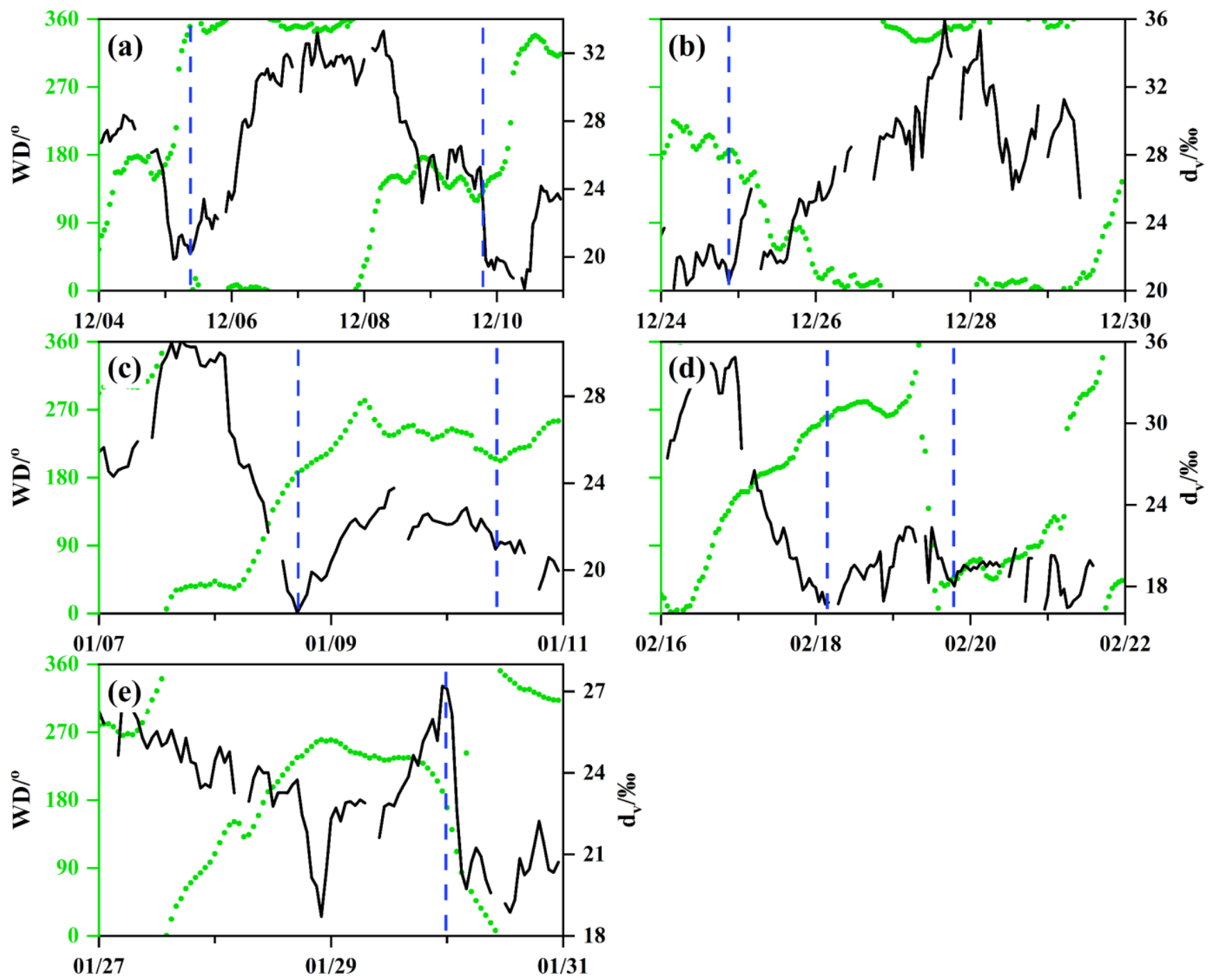

Fig 5. Time series of hourly water vapor $\mathrm{d}_{\mathrm{v}}$ (black lines) and $850 \mathrm{hPa}$ wind direction (green dots) of precipitation events. The vertical blue dashed lines indicate the different stages of precipitation events. (a) Event December 4-11, 2018; (b) Event December 24-30, 2018; (c) Event January 7-11, 2019; (d) Event February 16-22, 2019; (e) Event January 27-31, 2019. 